\title{
FINE STRUCTURE OF HALOPERIDOL BINDING SITES IN THE NEOSTRIATUM: AN ULTRAIMMUNOHISTOCHEMICAL ATTEMPT TO VISUALIZE HALOPERIDOL DOPAMINE REGEPTORS
}

\author{
HisANOBU KAIYA \\ Department of Neuropsychiatry, Gifu University School of Medicine \\ Gifu 500
}

Received for publication June 18, 1982 and in revised form November 2, 1982

\begin{abstract}
Following intrastriatal microinjection of haloperidol, the binding sites were demonstrated using ultraimmunohistochemistry. Haloperidol immunoreactive neurons began to appear $1 \mathrm{hr}$ after the injection and dispersed far from the injection site as time passed. Electron microscopically, haloperidol binding sites were visualized as a soluble form. The immunoreaction products were seen throughout the cytoplasm but avoided the nuclear membrane, cisternal structures and most of the mitochondria. The haloperidol immunoreaction products showed shading differences in each cytoplasm, which was understood to be due to various states of affinity to the ligand. Based on these findings, a new concept of receptors is proposed: There are spare receptors before functioning and active receptors having a higher affinity for the ligand.

Four out of six neuronal types in the rat neostriatum, according to the classification by Kaiya et al. $(13,15)$, showed haloperidol immunoreaction products.
\end{abstract}

While knowledge of neurotransmitter receptor is increasing, the concept of the receptor is still only a functional idea. The anatomical basis of the neuroleptic receptors, especially the fine structural characterization, is very limited at present, although some autoradiographic studies $(3,12)$ have been reported. If fine structural visualization of haloperidol binding sites is possible, the finding should provide further understanding of the dopamine receptors from a morphological view. The present study shows haloperidol binding sites in the rat neostriatum, using ultraimmunohistochemistry.

\section{METHODS}

Male Wistar albino rats, weighing 250-300 g, were used. Five $\mathrm{mg} / \mathrm{ml}$ haloperidol solution, commercially available from Dainippon Pharmaceutical Co. Ltd. was used in a concentration of $1.33-2.66 \mathrm{mM} / 1$, dissolved in distilled water. The animals were held in a stereotaxic apparatus under nembuthal anesthesia. $0.5 \mu \mathrm{l}$ of the neuroleptic solution, or physiological saline solution, was injected directly into the right neostriatum, according to the atlas of Pellegrino and Cushman (14), using a microinjector, for $30 \mathrm{~min}$. Immediately following the injection, and then 


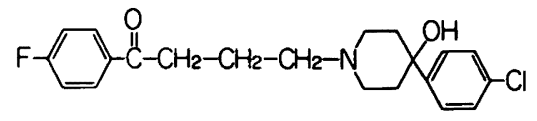

haloperidol

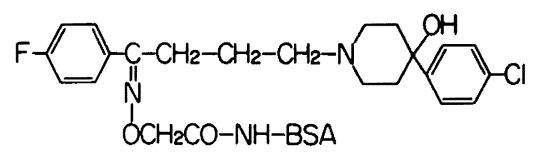

haloperidol conjugated with BSA

FIG. 1. Structures of haloperidol and antigen. BSA conjugate was used as an antigen. BSA: bovine serum albumin.

after $30,60,120$ and $180 \mathrm{~min}$, the animals were intracardially perfused with $0.05 \%$ glutaraldehyde and $2^{\circ}$, paraformaldehyde, buffered in $0.05 \mathrm{M}$ phosphate buffer solution, $\mathrm{pH}$ 7.2. After overnight immersion in the same fixative but without glutaraldehyde, $50 \mu \mathrm{m}$ vibratome sections, through the neostriatum, were rinsed in a phosphate buffer solution.

The antiserum was prepared by immunizing guinea pigs with haloperidol (Ocarboxymethyl) oxime derivative, coupled with bovine serum albumin (16) (Fig. 1). Conjugation of horseradish peroxidase (HRP) with the antibody for the haloperidol was performed, according to Nakane and Kawaoi (13). The sections were incubated for an hour in the HRP-labeled antiserum. After the incubation and rinse, the sections were transferred into a medium containing $0.01 \% 3,3^{\prime}$-diaminobenzidine tetrahydrochloride and $0.01 \% \mathrm{H}_{2} \mathrm{O}_{2}$, for visualization of HRP. Small pieces of the sections, containing HRP positive neurons, were excised selectively under a dissecting microscope and processed for electron microscopy, after $1 \mathrm{hr}$ of osmification. Ultrathin sections with or without lead staining, were viewed on a JEOL $100 \mathrm{~S}$ electron microscope. Some sections were prepared for examination under a light microscope.

\section{RESULTS}

Under light microscopic examination, the area stained with immunoreaction products in the neostriatum was restricted exclusively to the immediate vicinity of the haloperidol injected site, while no immunoreactivity was seen in the neostriatum injected with physiological saline solution. Around the injected site the neuropil was stained faintly (Fig. 2), and the neuron was darker (Figs. 3, 4). Immediately following the haloperidol injection, immunoreactive neurons could hardly be seen. As the survival time after the haloperidol injection went on, the immunoreactive staining of neuropil diminished, and the immunoreactive neurons dispersed far from the injected site. These immunoreactive neurons occasionally appeared to be

Figs. 2-4. Light microscopic immunohistochemistry of haloperidol binding sites in the rat neostriatum. $60 \mathrm{~min}$ after the haloperidol injection in the neostriatum.

FIG. 2. Neuropil around the injected traces is stained only faintly. IS: injected site. $\times 100$

FIG. 3. Neurons near the injected site (IS) having granular immunoreaction products. The nucleus avoids the reaction products. $\cdot 260$

Fig. 4. Immunoreactive neurons, stained homogenously, grouped in a cluster. $\times 260$ 
clustered (Fig. 4). Immunoreactive, medium-sized neurons were seen in ovoid or elliptical form. A few large, fusiform neurons appeared to have immunoreaction products. Immunoreaction products were stained homogenously in some neurons (Fig. 4) and granularly in others (Fig. 3). The correlation between these different features and the time course after haloperidol injection is unclear.
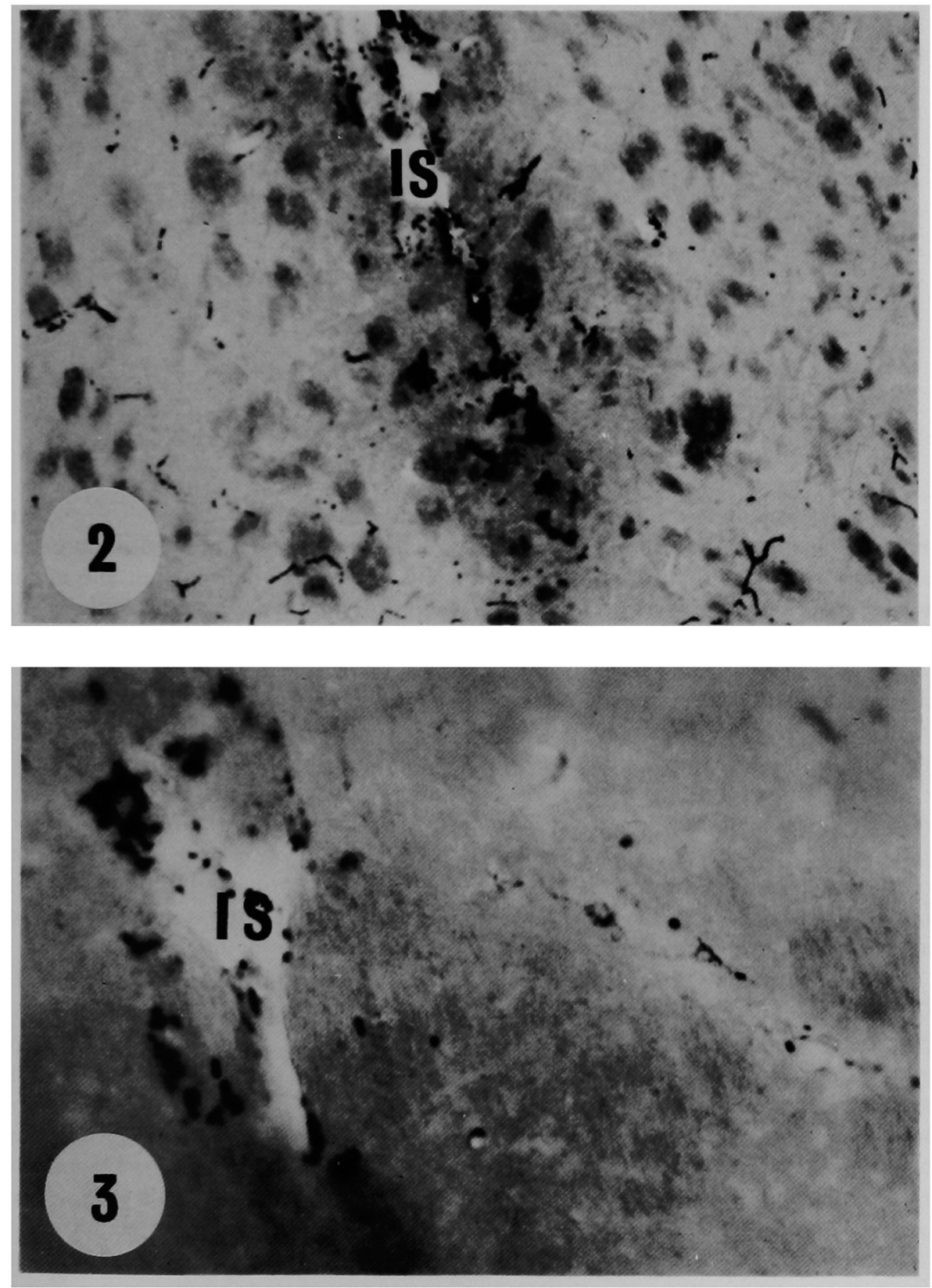


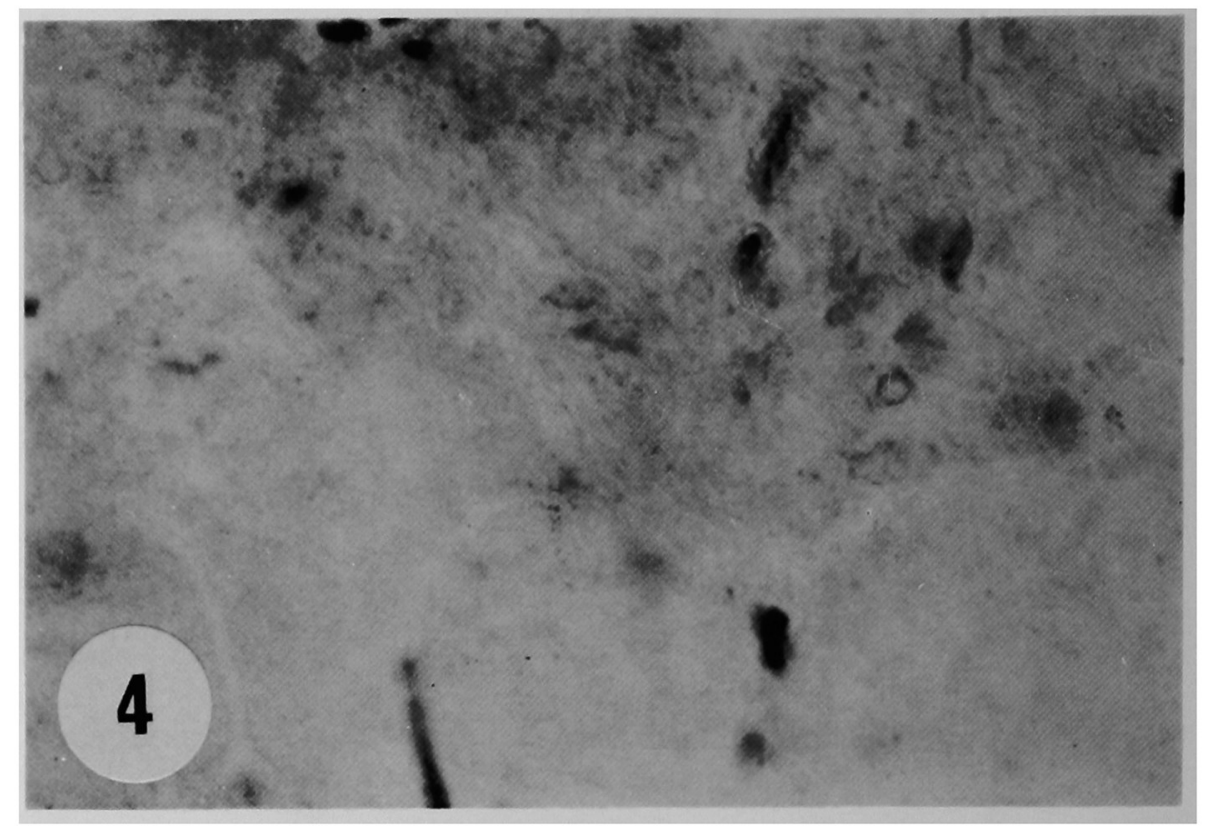

Under electron microscopic examination, haloperidol immunoreaction products were seen in the cytoplasm of the neuronal cell body and in the cytoplasm of the neuronal processes. Chromatins in the nucleus not only of neurons but also of glia showed unspecific positive reactions for the immunohistochemistry. Haloperidol immunoreaction products were seen in a soluble form throughout the neuronal cytoplasm except for the nuclear membrane, cisternal structures and most of the mitochondria. Darker, more pronounced immunoreaction products were observed occasionally in the cytoplasm, near the endoplasmic reticulum (arrow in Figs. 6, 7). The immunoreaction products were seen in the postsynaptic site of an axodendritic synapse, having a postsynaptic membranous thickening (Fig. 9). The prcsynaptic area was almost free from the immunoreaction products. Particular attention was paid in this instance to a small amount of immunoreaction products around the synaptic vesicles that exist near the presynaptic membrane (arrow in Fig. 9). The asterisk in Fig. 7 suggests the possibility that immunoreactive neuron receives an immunoreactive axon terminal, forming an axo-somatic synapse.

At least 4 out of 6 neuronal types in the rat neostriatum $(5,7)$ were revealed to show haloperidol immunoreactivity, that is, tyfcs I, II, III, and V. Type I neuron (Fig. 5 ) is medium-sized with a round or ovoid cell body. The cisternae of rough endoplasmic reticulum are short and sparsely distributed. Type II neuron (Fig. 6) has a large nucleus in proportion to the cytoplasm. The cytoplasm is also poor in the rough endoplasmic reticulum. The Type III neuron (Fig. 7) appears to be elliptical or triangular. The nuclear membrane has occasional indentation. In contrast to the types I and II neurons, the rough endoplasmic reticulum of this type is long. Type $\mathrm{V}$ (Fig. 8) is a large neuron with nuclear lobulation. Many rough endoplasmic reticula are grouped together and form a giant stack cluster. The halo- 

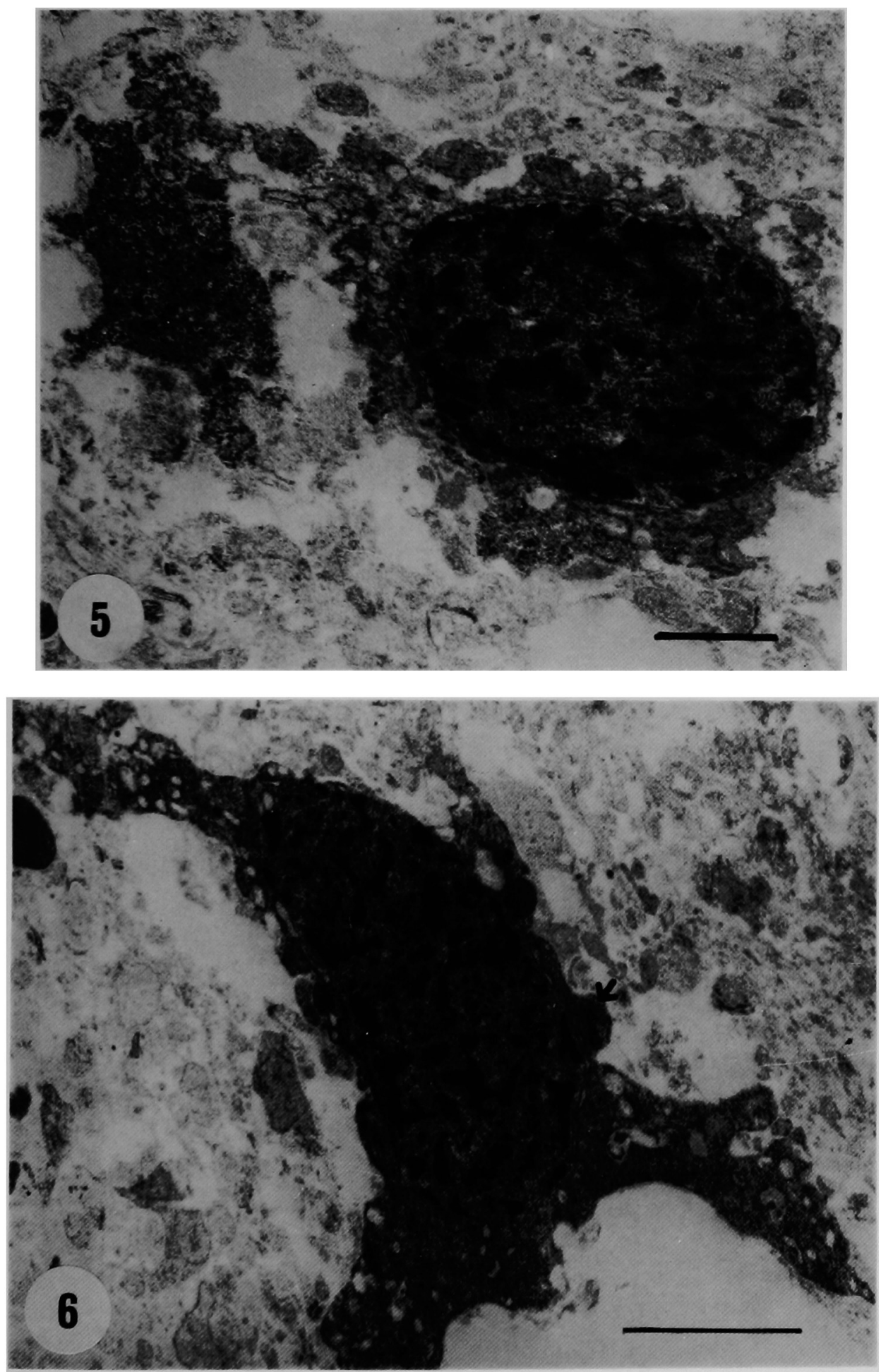

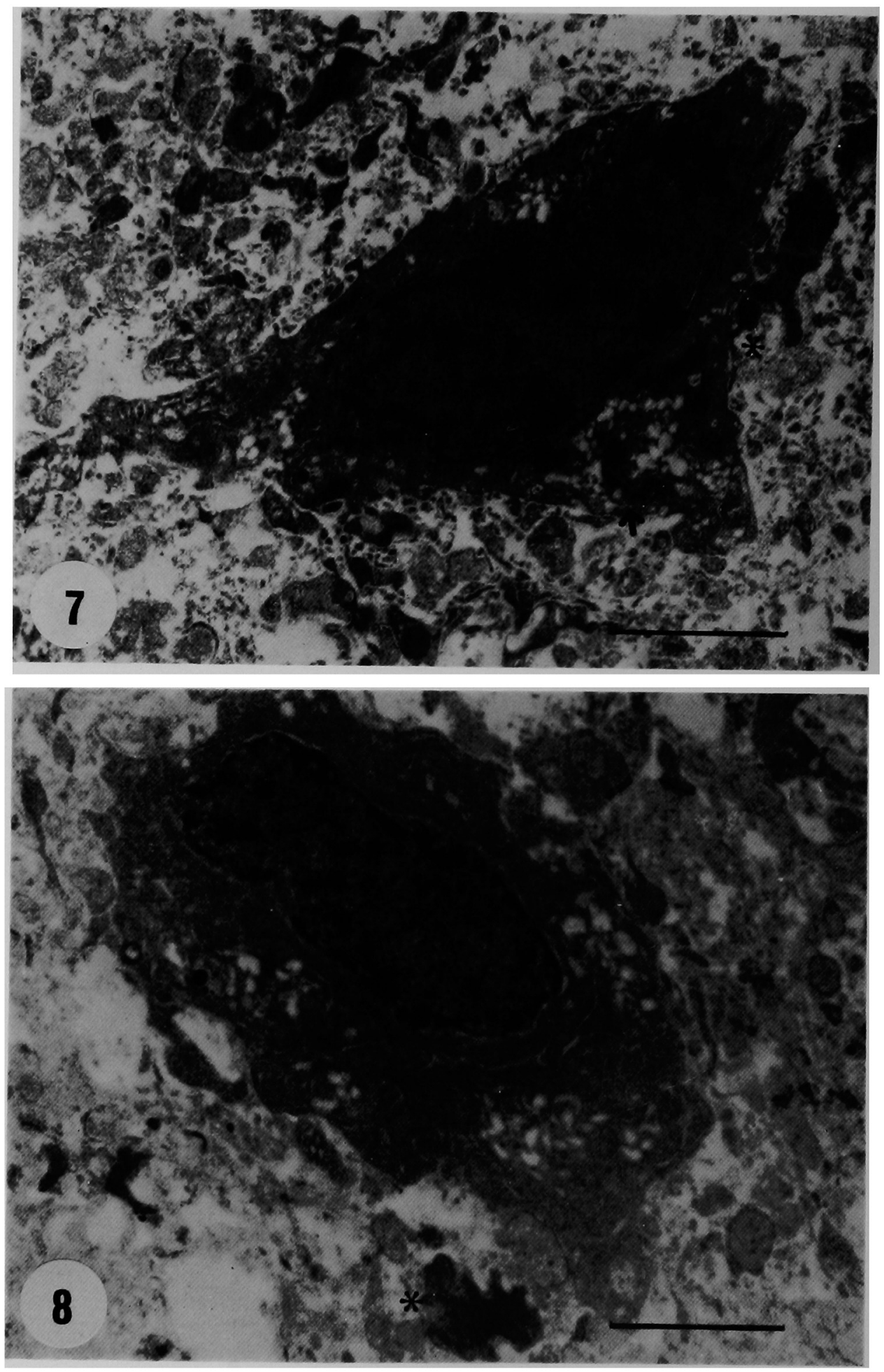


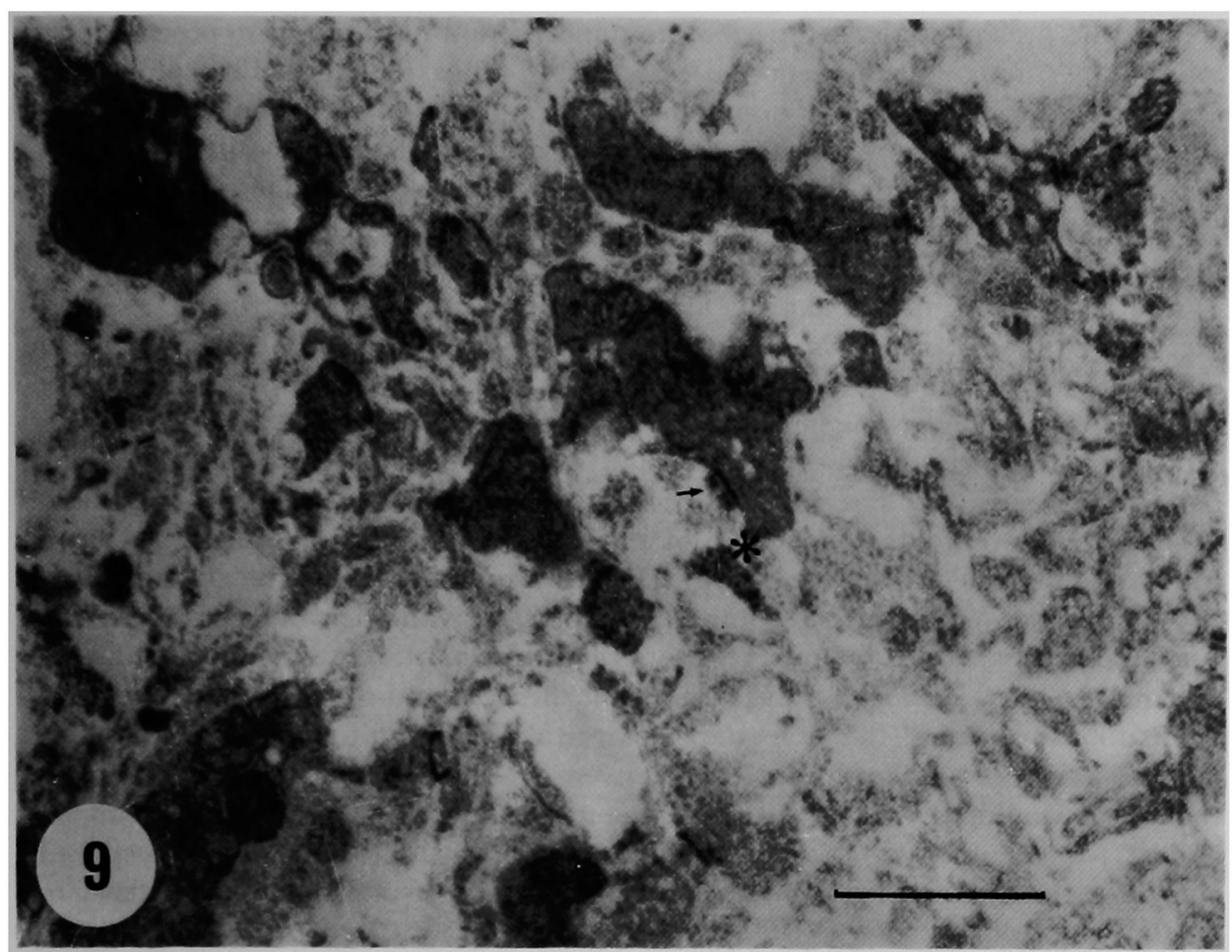

Figs. 5- 9. Electron micrography of haloperidol immunohistochemistry in the rat neostriatum. 60 min after haloperidol injection. Without lead staining.

Fic. 5. Type I, spiny interneuron showing haloperidol immunoreaction products throughout the cytoplasm. See the text. Bar $=2 \mu \mathrm{m}$

Fig. 6. Type II, interneuron with haloperidol immunoreactivity. See the text. Bar $=2 \mu \mathrm{m}$.

Fig. 7. Type III, efferent neuron with haloperidol immunoreactivity. See the text. Bar $=2 \mu \mathrm{m}$.

Fic. 8. Type $V$, large neuron with long axon showing relatively weak immunoreactivity. See the text. $\mathrm{Bar}=2 \mu \mathrm{m}$.

Fig. 9. Axo-dendritic synapse. Postsynaptic dendrite shows the reaction products. See the text. $\mathrm{Bar}=1 \mu \mathrm{m}$.

peridol immunoreaction products in the cytoplasm of the type $V$ neuron and relatively faint compared with the reaction prodects in the neuronal processes (asterisk) seen in the vicinity of this large neuron (Fig. 8).

\section{DISCUSSION}

The specificity of the antiserum for haloperidol used in the present study was established by Suzuki et al. (16). No other butyrophenone neuroleptics or metabolites of haloperidol appreciably cross-reacted with the antiserum. The dilution of the antiserum which exhibited $50^{\circ}{ }_{0}$ binding to the labeled antigen was $1: 3500$. The specificity of the immunohistochemical method was confirmed in the present study. Thus, the positive immunoreactive area was seen to be located exclusively around the antigen injected site, and there were no immunoreaction products after injection of physiological saline solution instead of haloperidol. 
In the present study haloperidol immunoreaction products were observed in a soupy state throughout the neuronal cytoplasm. Thus, haloperidol receptors could exist in the cytoplasmic sap of dopaminoceptive and possibly dopaminergic neurons. Although all specific binding sites to the ligand do not need to function as receptors, it is possible that specific binding sites would be ubiquitous in the cytoplasm of a given neuron. From this viewpoint the present findings are of great interest. Shading differences of immunoreaction products were seen in the neuronal soma (Figs. 6, 7) and between the neuronal soma and the neuronal process (Fig. 8). These findings suggest that there are various grades of affinity for haloperidol binding in each intraneuronal portion. The immunoreaction products were more pronounced in the vicinity of the rough endoplasmic reticulum where protein molecules are synthesized and also more pronounced in the neuronal processes which become postsynaptic sites. It has recently been reported that binding to ${ }^{3} \mathrm{H}$-enkephalin (17) and ${ }^{3} \mathrm{H}$-levetimide - a ligand for muscarinic receptors-(11) dammed up in the axon on both sides of the ligature. These authors considered the existence of an axoplasmic transport of the receptors. Based on these findings, haloperidol binding sites also are expected to undergo axoplasmic transport. It is plausible that the reaction products could be transported from the neuronal soma (synthesizing sites) to neuronal processes (function sites), where the function of receptors appears, for the first time, above the threshold of a given concentration. Here, it is proposed that there would be various states of receptors: spare receptors before functioning and active receptors with a higher affinity for the ligand. This new concept will compel a change in the conventional hypothesis, which often has schematized receptors as localizing only on the synaptic membrane.

The synapse with an asymmetric membranous thickening seen in Fig. 9 is thought to be dopaminergic and corresponds to type $\mathrm{A}$ in the classification of Kaiya and Namba (8) or type I of Bak et al. (1). The axon terminal showed almost no haloperidol immunoreaction products except for a small amount of the immunoreactivity around the synaptic vesicles, seen in the very vicinity of the synaptic membrane. This small amount of haloperidol immunoreaction products may implicate presynaptic DA receptor or autoreceptor (2) of the nigrostriatal DA pathway. Haloperidol was biochemically shown to bind to the presynaptic DA receptors. After both kanic acid lesions of the striatum, that destroys all neuronal perikaryon containing postsynaptic DA receptors, and cortical ablation, that avoids presynaptic DA receptors of corticostriatal afferents, $30 \%$ of the ${ }^{3} \mathrm{H}$-haloperidol binding in the neostriatum remained (15). This evidence suggests that some of the remaining striatal ${ }^{3} \mathrm{H}$-haloperidol binding sites are presynaptic receptors of the nigrostriatal DA pathway.

Four of 6 neuronal types in the neostriatum of our classification $(5,7)$ were shown to have haloperidol binding sites: Types I, II, III and V. Types I and II may be interneuron having CAT activity (5) and a small amount of AChE activity (7). Type I is a medium-sized, spiny neuron and thought to account for most of all striatal nerve cells. Detailed morphological differences between type I and II neuron have already been described $(7,10)$. Both neuronal types were shown to form axo-somatic synapse with nerve terminals containing CAT positive synaptic vesicles (5). Thus, types I and II neurons are at the same time cholinergic and cholinoceptive (Fig. 10). In the present study it was shown that types I and II neurons have haloperidol bind- 


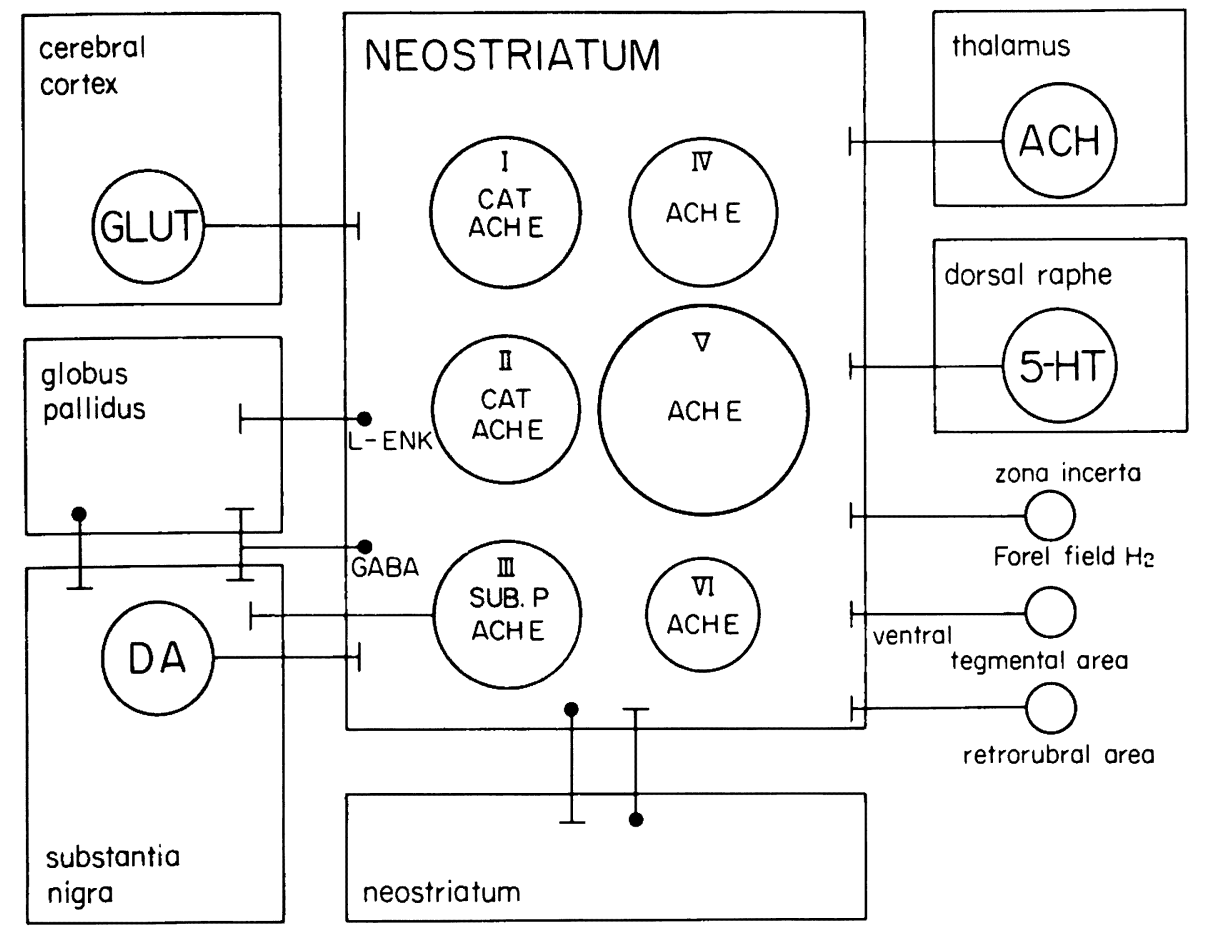

Fic. 10. A tentative schematic model of neuronal network in the neostriatum. Shadowed neurons represent haloperidol binding sites.

ing sites. It implies that these two types of cholinergic interneurons are the postsynaptic sites of DA neural transmission. The present result is directly supportive of our previous study which demonstrated that types I and II cholinergic neurons synapsed in an axo-somatic form with degenerated DA nerve terminals, after destruction of the ipsilateral substantia nigra (8). Types III and V neurons were shown to receive axo-somatic synapse with CAT positive axon terminals (5). Abundant AChE activity was seen in both these neuronal types (7). The authors have demonstrated that HRP injected in the substantia nigra was retrogradely transported to type III neuron in the neostriatum (6). Furthermore, we have recently found substance P immunoreactivity in type III neuron (9). In summary, type III neuron is striato-nitral efferent, cholinoceptive and dopaminoceptive, and showed immunoreactivity of substance $P$. Thus, results of the present study are consistent with reported pharmacological findings suggesting that cholinergic and substance P-ergic neurons become postsynaptic sites of dopamine neural transmission in the neostriatum.

\section{REFERENCES}

1. Bak, I. J., Choi, W. B., Hassler, R., Usunoff, K. G. and Wagner, A.: Fine structural synaptic organization of the corpus striatum and substantia nigra in rat and cat. In Advances in Neurology, vol. 9., ed. by D. B. Calne, T. N. Chase and A. Barbeau, Raven Press, New York, 1975, 
p. $25-41$.

2. Carlsson, A.: Receptor-mediated control of dopamine metabolism. In Pre- and Postsynaptic Receptors, ed. by E. Usdin and W. E. Bunney, Marcel Dekker, New York, 1975, p. 49-65.

3. Höllt, V. and Schubert, P.: Demonstration of neuroleptic receptor sites in mouse brain by autoradiography. Brain Res. 151; 149-153, 1978.

4. Kaiya, H.: Fine structure of target neurons of antischizophrenic drugs in the neostriatum. Ultracytochemical observation of dopamine and acetylcholine interaction. Folia Psychiat. Neurol. Jpn. 33: 223-232, 1979.

5. Kaiya, H., Iwata, T., Namba, M., Ago, Y., Mayahara, H. and Ogawa, K: Ultracytochemistry of choline acetyltransferase in the neostriatum of the rat brain. Acta histochem. cytochem. 12; 391-404, 1979.

6. Kaiya, H., Okinaga, M., Namba, M., Shoumura, K. and Watanabe, S.: Ultrastructure of acetylcholinesterase containing striato-nigral neurons transporting HRP retrogradely. Neurosci. Letters $14 ; 7-11,1979$.

7. Kaiya, H., Kreutzberg, G. W. and Namba, M.: Ultrastructure of acetylcholinesterase synthesizing neurons in the neostriatum. Brain Res. 187; 369-382, 1980.

8. Kaiya, H. and Namba, M.: Two types of dopaminergic nerve terminals in the rat neostriatum: An ultrastructural study. Neurosci. Letters 25; 251-256, 1981.

9. Kaiya, H. and Namba, M.: Fine structure of haloperidol binding sites in the neostriatum with a special reference to substance $P$ and $\gamma$-aminobutyric acid (GABA) system in schizophrenia. In Psychobiology of Schizophrenia, ed. by M. Namba and H. Kaiya, Pergamon Press, Oxford, 1982, p. 31-44.

10. Kemp, J. M. and Powell, T. P. S.: The structure of the caudate nucleus of the cat: Light and electron microscopy. Phil. Trans. R. Soc. Lond. 262; 383-401, 1971.

11. Laduron, P.: Axoplasmic transport of muscarinic receptors. Nature 286: 287-288, 1980.

12. Murrin, L. C., Gale, K. and Kuhar, M. J.: Autoradiographic localization of neuroleptic and dopamine receptors in the caudate-putamen and substantia nigra: Effects of lesions. Eur. J. Pharmacol. 60; 229-235, 1979.

13. Nakane, P. K. and Kawaoi, A.: Peroxidase-labeled antibody. A new method of conjugation. J. Histochem. Cytochem. 22; $1084-1091,1974$.

14. Pellegrino, L. J. and Cushman, A. J.: A Stereotaxic Atlas of the Rat Brain. Appleton-CenturyCrofts, New York, 1967.

15. Schwarcz, R., Creese, I., Coyle, J. T. and Snyder, S. H.: Dopamine receptors localized on cerebral cortical afferents to rat corpus striatum. Nature $271 ; 766-768,1978$.

16. Suzuki, H., Minaki, Y., Iwasaki, M., Sekine, Y., Kagemoto, A., Utsui, Y., Hashimoto, M., Yagi, G. and Itoh H.: Determination of haloperidol in human serum by radioimmunoassay. $J$. Pharm. Dyn. 3; 250-257, 1980.

17. Young, W. S., Wamsley, J. K., Zarbin, M. A. and Kuhar, M. J.: Opioid receptors undergo axonal flow. Science $210 ; 76-78,1980$. 